\title{
Frogs in the Genus Fejervarya (Anura: Dicroglossidae) of the Nazipur Area, Patnitala Upazila, Naogaon District in Northwestern Bangladesh
}

Faysal Ahmad and Shayer Mahmood Ibney Alam

Department of Zoology, Jagannath University, Dhaka-1100, Bangladesh (faysal.nature@gmail.com)

Photographs by the senior author

$\mathrm{B}^{2}$ angladesh, located at the junction of the Indo-Himalayan and Indo-Chinese Subregions (Stanford 1991) and part of the Indo-Burmese biodiversity hotspot (Myers et al. 2000), has a rich biota. Hasan et al. (2014) recorded 71 species of amphibians, including nine species in the genus Fejervarya. Frogs in this genus, variously referred to as Terrestrial Frogs, Cricket Frogs, or Wart Frogs, are assigned to the family Dicroglossidae, subfamily Dicroglossinae, and include 39 currently recognized species of small to medium-sized frogs distributed widely over southern and southeastern Asia (Frost 2015). These frogs are characterized by the presence of the "Fejervarya line" on both sides of the belly and the absence of a rictal gland at the mouth commissure. In earlier publications, most species were referred to Rana limnocharis, a species as then defined with a wide range extending from Pakistan to China, Japan, and Indonesia. After reassignment to the genus Fejervarya, the name F. limnocharis was restricted to populations in Indonesia and Malaysia (Dubois and Ohler 2000; Veith et al. 2001).

The slight morphological differences among the species in this genus have generated some confusion; consequently, various species have been collectively identified as belonging to the Fejervarya limnocharis complex (e.g., Islam et al. 2008). However, biochemical and molecular phylogenetic analyses clearly illustrate the presence of several cryptic species in the genus from the South Asian Region (Toda et al. 1998; Kurabayashi et al. 2005; Djong et al. 2007; Hasan et al. 2012). Kuramoto et al. (2007) described four cryptic species from the Western Ghats of India, and Howlader (2011a) discovered two previously unknown species in Bangladesh (Fejervarya frithii from Jessore and $F$. asmati from Chittagong). Note, however, Howlader (2011b) subsequently recognized distinct South Asian and Southeast Asian morphs and assigned several species to the genus Zakerana. Herein, however, we follow Frost (2015) in retaining the name Fejervarya for all species.

\section{Methods}

Our study site (Fig. 1) was at Nazipur Area, Patnitala Upazila, Naogaon District $\left(25^{\circ} 2^{\prime} 42.23^{\prime \prime} \mathrm{N}, 88^{\circ} 45^{\prime} 4.47^{\prime \prime}\right.$; elevation 24 $\mathrm{m}$ asl). We conducted surveys in known Fjervarya habitats along ponds, rivers, canals, temporary pools, paddy fields, and wet grasslands. We spent 27 nights from 1930-1130 h searching for amphibians in June-September 2013 and collected one representative specimen of each species to compare morphometric data with previously published reports by Borthakur et al. (2007; for F. nepalensis, F. pierrei, and F. teraiensis), Howlader (2011a; for F. asmati), and Kurniawan et al. (2011; for F. cancrivora).

Based on morphological and morphometric descriptions in the sources listed above and supplemented by those in Dubois (1975, 1984), Schleich and Kästle (2002), Islam et al. (2008), Howlader (2011b), and Hasan et al. (2014), we used eleven parameters for species identification: SVL (snout-vent length), HL (head length), HW (head width), SL (snout length), IN (internarial distance), EN (distance from front of eyes to nostril), NS (nostril-snout length), EL (eye length), TL (tibial length), finger formula, and tubercle arrangements. We used digital calipers to take measurements of the representative individual of each species after confirmation of identity.

\section{Results}

During our surveys, we encountered five species in the genus Fejervarya. All measurements are in mm. (1) Nepal Cricket Frog (Fejervarya nepalensis [Dubois 1975]); Fig. 2. Adult female: SVL 38.5; HL 11.5; HW 10.2; SL 6.00; IN 3.2; EN 3.00; NS 2.4; EL 5.00; TL 17.00. Small frogs with a distinct narrow middorsal line (MDL), sometimes absent. Skin fringe indistinct on outer side of 5 th toe. Right finger length (RFL) $2<1<4<3$. Body tubercles 


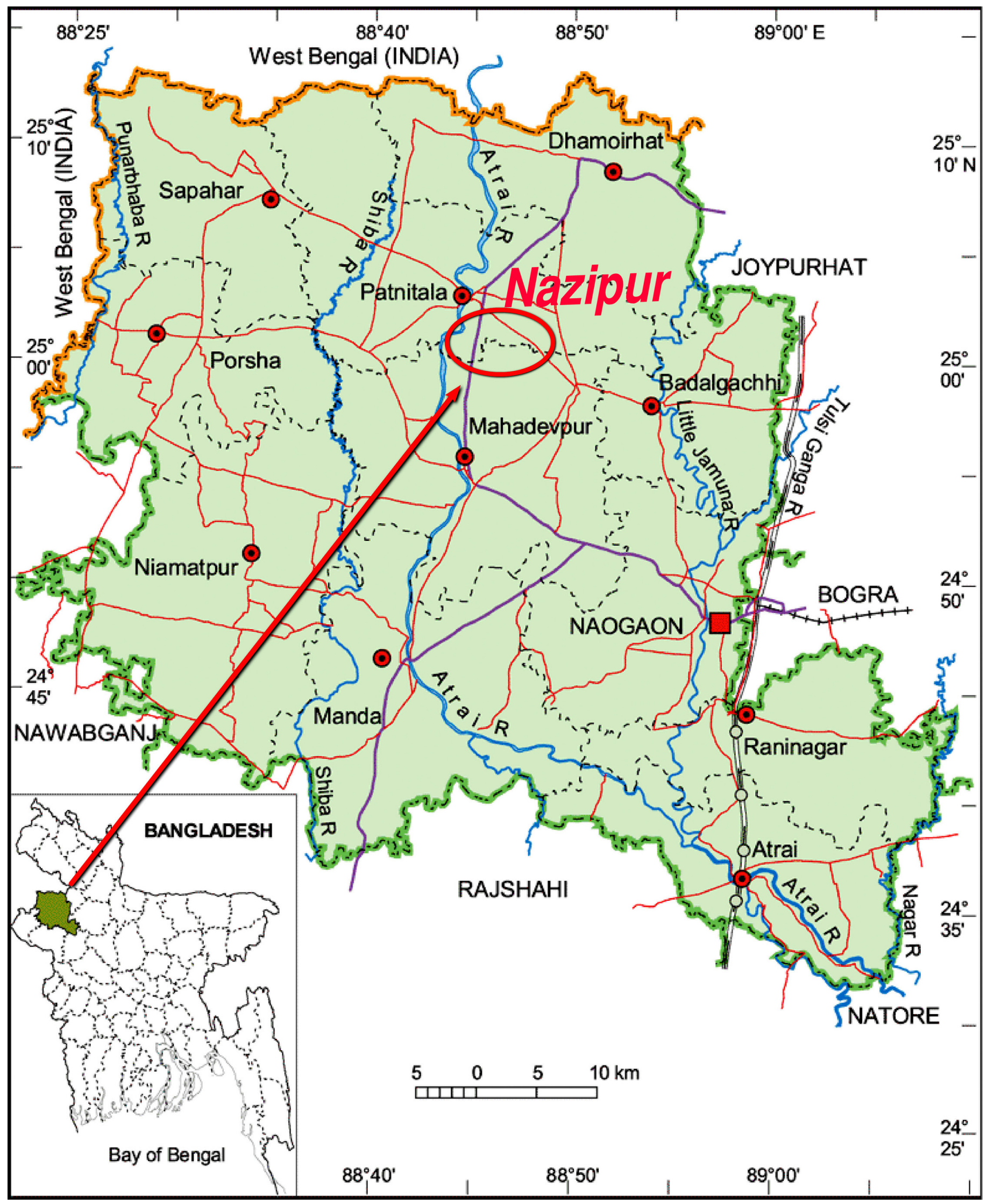

Fig. 1. Location of the study area in the Nazipur Area of Bangladesh. 
oblong, arranged in longitudinal folds; snout jutting over lower jaw. Collected from the bank of a small pond covered with grasses. (2) Pierre's Cricket Frog (Fejervarya pierrei [Dubois 1975]); Fig. 3. Adult male: SVL 40.00; HL 13.8; HW 12.00; SL 5.8; IN 2.2; EN 3.00; NS 3.2; EL5.6; TL 17.00. Small frogs with a distinct wide middorsal line (MDL) extending from tip of snout to vent. Skin fringe not present on outer side of 5 th toe. Right finger length (RFL) $2=4<1<3$ ( 1 st finger longer than 2 nd and 4 th). Throat dark laterally and pale medially in male. Body tubercles oblong, arranged in rows; snout tip markedly jutting over lower jaw. Collected from the edge of a temporary pool. (3) Terai Cricket Frog (Fejervarya teraiensis [Dubois 1984]); Fig. 4. Adult male: SVL 50.00; HL 8.5; HW 17.00; SL 9.5; IN 4.00; EN 5.2; NS 4.2; EL 7.5; TL 21.4. Large frogs with highly variable middorsal lines (MDL) (i.e., present-absent; if present, distinct to indistinct, narrow to broad, same width throughout or irregularly broad). Distinct skin fringe on outer side of 5 th toe. Right finger length (RFL) $2=4<1<3$ ( 1 st finger distinctly longer than 2 nd and 4th. "W" shaped dark mark on throat of male. Snout scarcely jutting over lower jaw. Collected

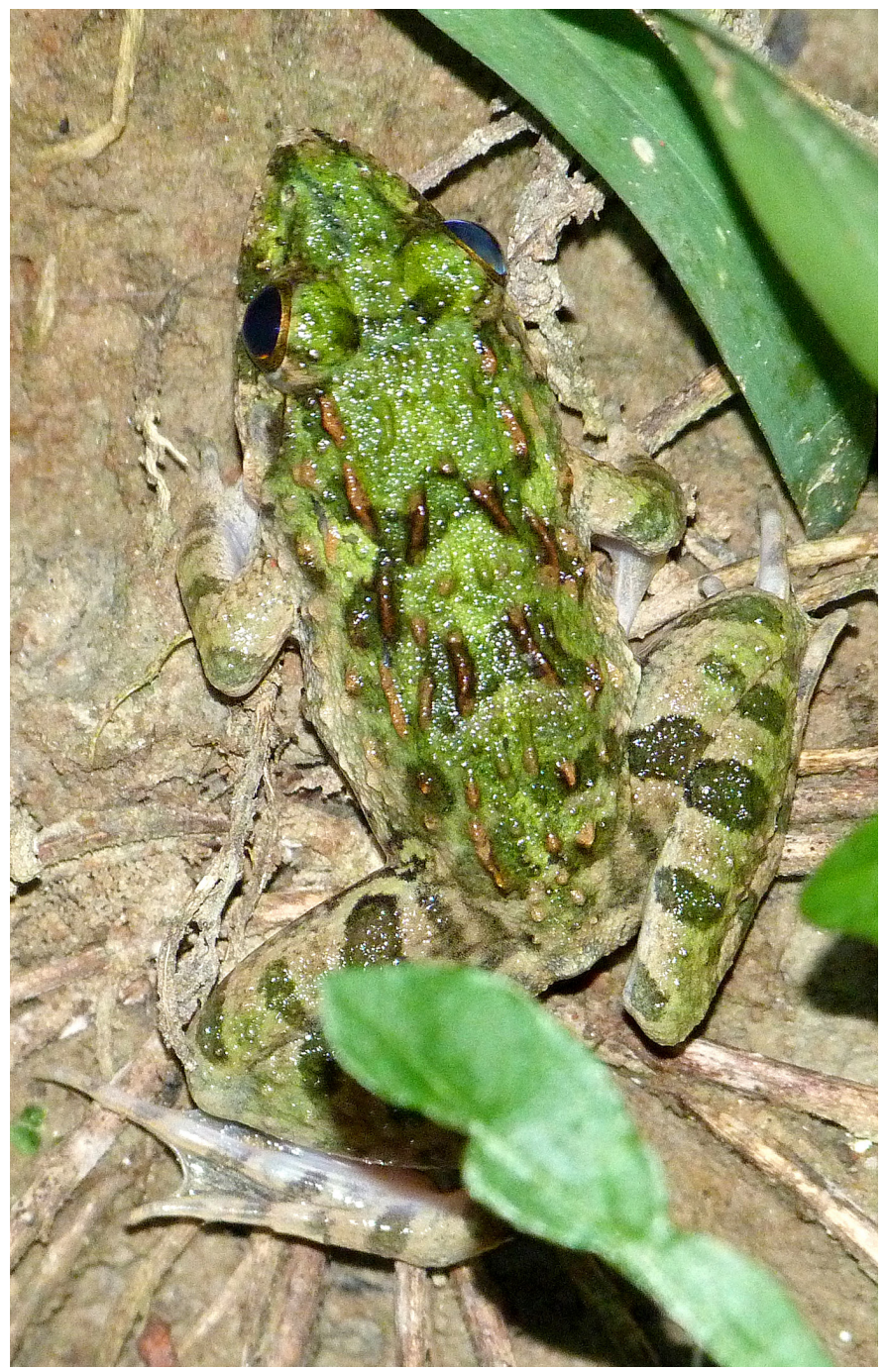

Fig. 2. Nepal Cricket Frog (Fejervarya nepalensis). among bushes and grasses along the bank of a stream. (4) Asmat's Cricket Frog (Fejervarya asmati Howlader 2011); Fig. 5. Adult female: SVL 31.5; HL 11.6; HW 10.6; SL 5.2; IN 3.1; EN 3.8; NS 2.1; EL 4.5; TL 16.3. Small frogs also with distinct narrow middorsal lines (MDL). Right finger length (RFL) $2<4<1<3$. Tips of fingers bluntly rounded and fingers lacking dermal ridges. Sub-articular tubercles prominent, rounded, single tubercle per digit; two distinct capsule-shaped palmar tubercles; supernumerary tubercles absent. Nostrils much closer to snout tip than eyes. Collected from an open area adjacent to a canal. (5) Mangrove Frog (Fejervarya cancrivora [Gravenhorst 1829]); Fig. 6. Adult female: SVL 69.00; HL 21.9; HW 23.5; SL 8.5; IN 3.9; EN 5.5; NS 4.3; EL 7.0; TL 35.0. Larger than other four species. Head comparatively narrow with oval snout. Right finger length (RFL) $2<4<3<1$. Fingers without dermal fringes. Toes almost pointed, web almost reaching tips on outer borders of 1 st, 2 nd, and 3 rd toes, inner border of 5 th toe, and outermost tubercle of 4 th toe. Irregular longitudinal ridges present on back. Collected from a wet grassland bordering rice paddies.

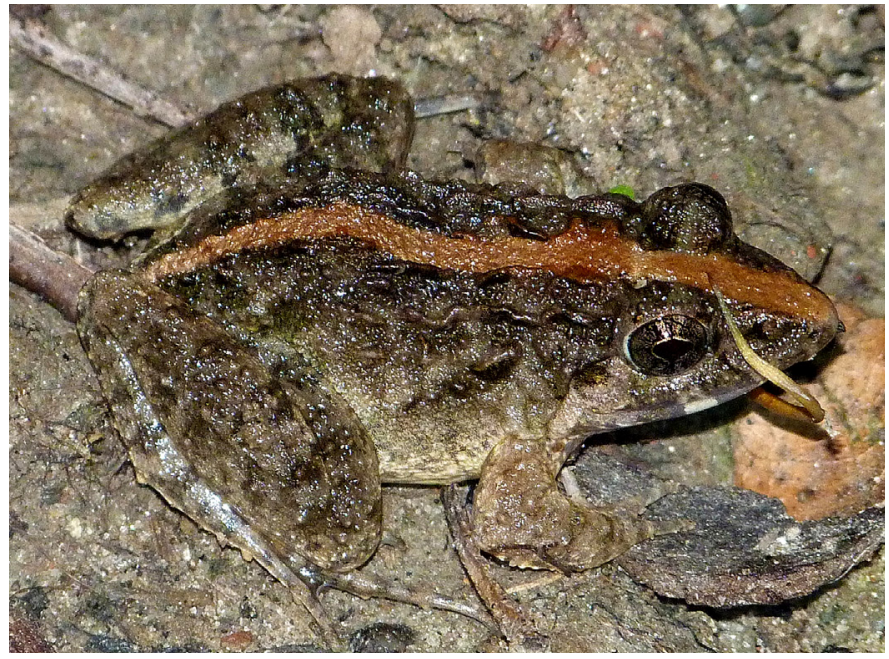

Fig. 3. Pierre's Cricket Frog (Fejervarya pierrei).

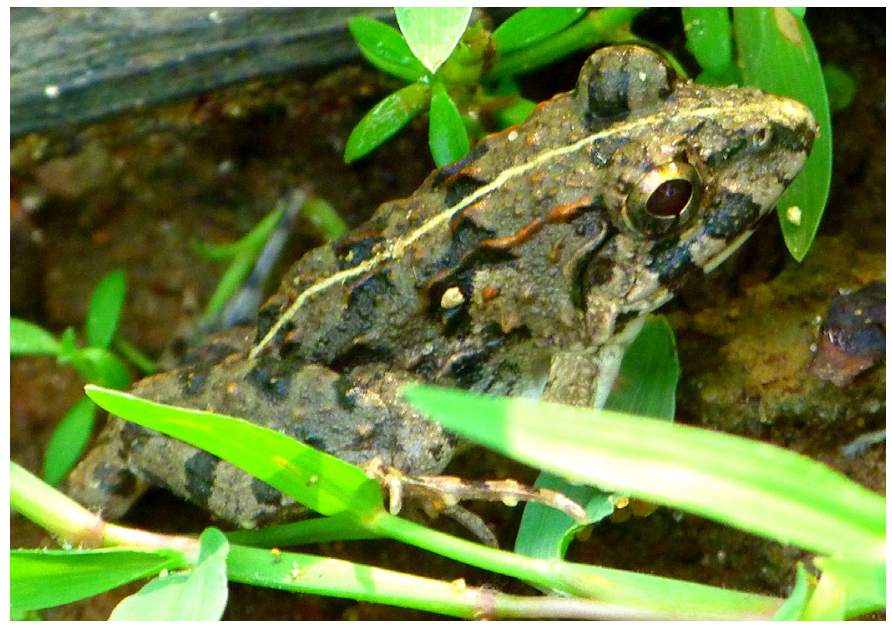

Fig. 4. Terai Cricket Frog (Fejervarya teraiensis). 


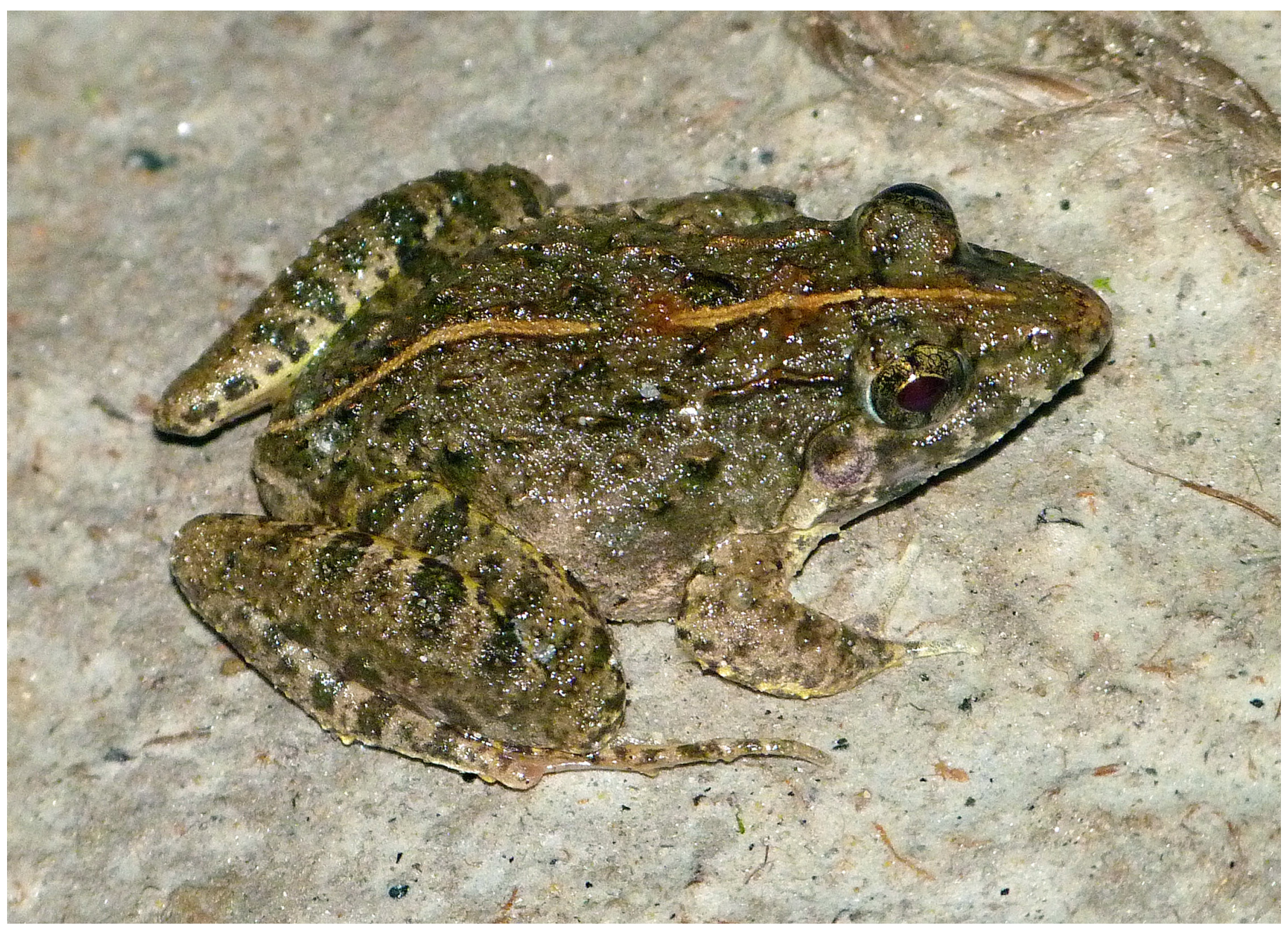

Fig. 5. Asmat's Cricket Frog (Fejervarya asmati).

\section{Discussion}

According to Hasan et al. (2014), nine species occur in Bangladesh, over half of which are present in our study area, suggesting that this site supports a high diversity of amphibians. Further investigations are likely to reveal more species in the genus Fejervarya from this region.

Frogs are highly sensitive to environmental changes that can lead to extinction, and frequently are considered accurate indicators of environmental stress. Excessive exploitation of natural resources (i.e., cutting vegetation, flooding bodies of water, and widespread use of pesticides), an expanding human footprint corresponding to a growing human population, diseases, climate change, and increases in UV radiation might be affecting amphibian populations in the region, lending urgency to the need for more surveys, detailed studies, and implementation of measures for conserving amphibians in rapidly degrading habitats.

\section{Acknowledgements}

The authors are highly grateful to our parents for supporting our research and the Department of Zoology, Jagannath University for providing laboratory space and access to equipment. We also thank Kathleen Ninneman and Hector Hinojosa for providing financial support for fieldwork; Prof. Dr. Ghazi Asmat, Prof. Dr. Monirul H. Khan, Dr. Ummay Habiba Khatun, Mohammad Abdul Wahed Chowdhury, Stephen Mahony, Delip K. Das, Christopher E. Smith and M. Sajid Ali Howlader for providing information and access to the literature; and the Nature Study and Conservation Club of the Department of Zoology, Jagannath University for general support.

\section{Literature Cited}

Borthakur, R., J. Klita, B. Hussain, and S. Sengupta. 2007. Study on the Fejervarya (Anura: Dicroglossidae) species of Assam. Zoos' Print Journal 22:2639-2643.

Djong, H.T., M.M. Islam, M. Nishioka, M. Matsui, H. Ota, M. Kuramoto, M.M.R. Khan, M.S. Alam, A. De Silva, W. Khonsue, and M. Sumida. 2007. Genetic relationships and reproductive isolation mechanism among the Fejervarya limnocharis complex from Indonesia (Java) and other Asian countries. Zoological Science 24:360-375.

Dubois, A. 1975. Un nouveau complexe d'espèces jumelles distinguées par le chant: les grenouilles du Népal de Rana limnocharis. Boie (Amphibiens: Anoures). Comptes Rendus de l'Académie des Sciences (D) 281:1717-1720.

Dubois, A. 1984. Note preliminaire sur le groupe de Rana limnocharis Gravenhorst, 1829 (Amphibiens: Anoures). Alytes 3:143-159.

Dubois, A. and A. Ohler. 2000. Systematics of Fejervarya limnocharis (Gravenhorst, 


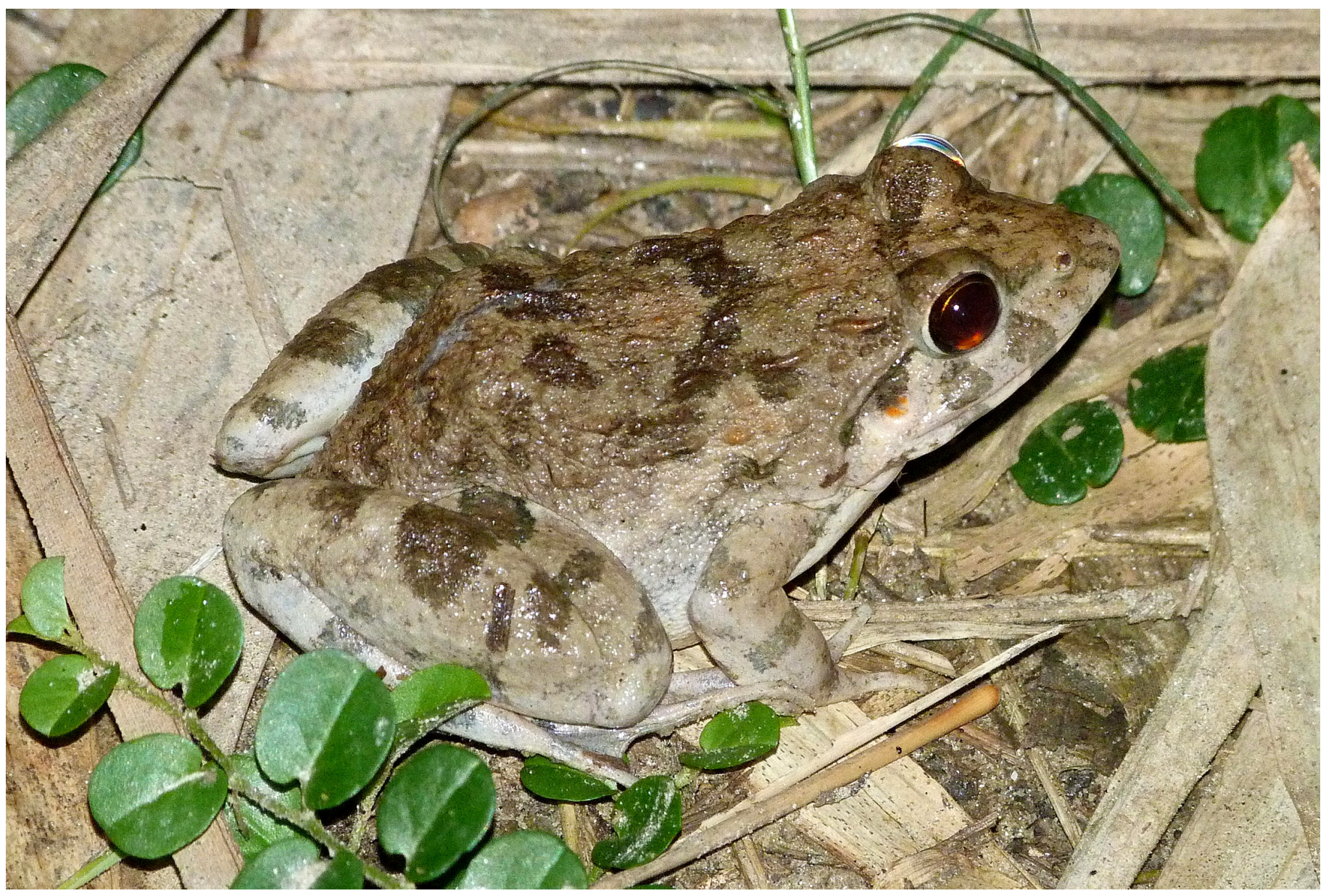

Fig. 6. Mangrove Frog (Fejervarya cancrivora).

1829) (Amphibia, Anura, Ranidae) and related species. 1. Nomenclatural status and type-specimens of the nominal species Rana limnocharis Gravenhorst, 1829. Alytes 18:15-50

Frost, D.R. 2015. Amphibian Species of the World: An Online Reference. Version 6.0. American Museum of Natural History, New York. <http://research.amnh. org/herpetology/amphibia/index.html>.

Hasan, M.K., M.M. Islam, M.M.R. Khan, M.S. Alam, A. Kurabayashi, T. Igawa, M. Kuramoto, and M. Sumida. 2012. Cryptic anuran biodiversity in Bangladesh revealed by mitochondrial $16 \mathrm{~S}$ rRNA gene sequences. Zoological Science 29:162-172.

Hasan, M.K., M.M.H. Khan, and M.M. Feeroz. 2014. Amphibians and Reptiles of Bangladesh - A Field Guide. Arannayk Foundation, Dhaka, Bangladesh.

Howlader, M.S.A. 2011a. A new species of Fejervarya (Anura: Dicroglossidae) from Bangladesh. Zootaxa 2761:41-50.

Howlader, M.S.A. 2011b. Cricket Frog (Amphibia: Anura: Dicroglossidae): Two regions of Asia are corresponding two groups. BONNOPRANI-Bangladesh Wildlife Bulletin 5:1-7.

Islam, M.M., N. Kurose, M.M.R. Khan, T. Nishizawa, M. Kuramoto, M.S. Alam, M. Hasan, N. Kurniawan, M. Nishioka, and M. Sumida. 2008. Genetic divergence and reproductive isolation in the genus Fejervarya (Amphibia: Anura) from Bangladesh inferred from morphological observation, crossing experiments, and molecular Analyses. Zoological Science 25:1084-1105.

Kurabayashi, A., M. Kuramoto, H. Joshi, and M. Sumida. 2005. Molecular phylogeny of the ranid frogs from southwest India based on the mitochondrial ribosomal RNA gene sequences. Zoological Science 22:525-534.

Kuramoto, M., S.H. Joshy, A. Kurabayashi, and M. Sumida. 2007. The genus Fejervarya (Anura: Ranidae) in Central Western Ghats, India, with description of four new cryptic species. Current Herpetology 26:81-105.

Kurniawan, N., T.H. Djong, M.M. Islam, T. Nishizawa, D.M. Belabut, Y.H. Sen, R. Wanichanon, I. Yasir, and M. Sumida. 2011. Taxonomic status of three types of Fejervarya cancrivora from Indonesia and other Asian countries based on morphological observations and crossing experiments. Zoological Science $28: 12-24$.

Myers, N., R.A. Mittermeier, C.G. Mittermeier, G.A.B. da Fonseca, and J. Kent. 2000. Biodiversity hotspots for conservation priorities. Nature 403:853-858.

Schleich, N.H. and W. Kästle (eds.). 2002. Amphibians and Reptiles of Nepal. A.R.G. Gantner Verlag K.G., Ruggell, Liechtenstein.

Stanford, C.B. 1991. The Capped Langur in Bangladesh: Behavioral Ecology and Reproductive Tactics. Contributions to Primatology, Volume 26. Karger Publishers, Basel, Switzerland.

Toda, M., M. Matsui, M. Nishida, and H. Ota. 1998. Genetic divergence among southeast and east Asian populations of Rana limnocharis (Amphibia: Anura, with special reference to sympatric species in Java. Zoological Science 15:607-613.

Veith, M., J. Kosuch, A. Ohler, and A. Dudois. 2001. Systematics of Fejervarya limnocharis (Gravenhorst, 1829) (Amphibia: Anura: Ranidae) and related species. 2. Morphological and Molecular variations in frogs from the greater Sunda Island (Sumatra, Java, Borneo) with the definition of two species. Alytes 19:5-28. 